\title{
CHILDREN AND HOUSEHOLD UTILITY: EVIDENCE FROM KIDS FLYING THE COOP
}

Norma B. Coe and Anthony Webb

CRR WP 2010-16

Date Released: November 2010

Date Submitted: October 2010

\author{
Center for Retirement Research at Boston College \\ Hovey House \\ 140 Commonwealth Avenue \\ Chestnut Hill, MA 02467 \\ Tel: 617-552-1762 Fax: 617-552-0191 \\ http://crr.bc.edu
}

Norma B. Coe is associate director of research at the Center for Retirement Research at Boston College (CRR). Anthony Webb is a research economist at the CRR. The research reported here was performed pursuant to a grant from the U.S. Social Security Administration (SSA) funded as part of the Retirement Research Consortium (RRC). The opinions and conclusion expressed are solely those of the authors and do not represent the opinions or policy of SSA, any agency of the federal government, the RRC, or Boston College. The authors would like to thank Geoff Sanzenbacher and Zhenya Karamcheva for excellent research assistance, and Peter Gottschalk, Erik Hurst, and Adriaan Kalwij for helpful comments on earlier drafts. All errors are our own.

(C) 2010, by Norma B. Coe and Anthony Webb. All rights reserved. Short sections of text, not to exceed two paragraphs, may be quoted without explicit permission provided that full credit, including (C) notice, is given to the source. 


\title{
About the Center for Retirement Research
}

The Center for Retirement Research at Boston College, part of a consortium that includes parallel centers at the University of Michigan and the National Bureau of Economic Research, was established in 1998 through a grant from the Social Security Administration. The Center's mission is to produce first-class research and forge a strong link between the academic community and decision makers in the public and private sectors around an issue of critical importance to the nation's future. To achieve this mission, the Center sponsors a wide variety of research projects, transmits new findings to a broad audience, trains new scholars, and broadens access to valuable data sources.

\section{Center for Retirement Research at Boston College}

\author{
Hovey House \\ 140 Commonwealth Avenue \\ Chestnut Hill, MA 02467 \\ phone: 617-552-1762 fax: 617-552-0191 \\ e-mail: crr@bc.edu \\ crr.bc.edu
}

Affiliated Institutions:

The Brookings Institution

Massachusetts Institute of Technology

Syracuse University

Urban Institute 


\begin{abstract}
Using consumption and wealth data from the Health and Retirement Study (HRS), this paper explores the impact of children leaving home on household consumption. We find that households maintain their household-level consumption, despite the fact that the number of individuals in the household has decreased, increasing per-capita consumption. Further, we find no evidence of increases in total net wealth, or any of its components, after children leave the household. These findings suggest that households do not dramatically change their savings or consumption patterns when their children fly the coop. Those households who are already behind in their retirement preparations will remain at risk of entering retirement with insufficient wealth to maintain their pre-retirement standard of living.
\end{abstract}




\section{Introduction}

With the disappearance of traditional pensions, declining Social Security replacement rates, and increases in longevity, the retirement landscape is shifting dramatically. Today, responsibility for a comfortable retirement rests mostly on the individual. This has led to widespread concern, and disagreement, about the adequacy of American households’ retirement savings. Munnell, Golub-Sass, and Webb (2007) estimate that 43 percent of households are at risk of being unable to maintain their pre-retirement standard of living in retirement. In contrast, Scholz and Seshadri (2008) estimate that less than 4 percent of households are saving inadequately for retirement.

Estimates of the financial preparedness for retirement of middle-aged households depend crucially on projections of the amounts households will save in the years leading up to retirement. Many changes occur during these years that may impact one's ability to save for retirement: children attaining financial independence being perhaps the most significant. If households are not liquidity constrained and financial independence of offspring is a predictable event, households should be able to smooth their marginal utility of consumption notwithstanding these changes in household composition. However, it is still unclear how family size impacts utility, or how children, or their consumption, enter into the utility function. The most common assumption is that consumption of family members is separable in the utility function. If this is the case, then the marginal utility of consumption is constant over time when (per-equivalent) adult consumption is constant over time. This formulation of the utility function has two important implications for retirement savings decisions. First, if income peaks between ages 40 and 60, and if expenses of child rearing peak at younger ages, then households should do most of their retirement saving after age 40. Second, families who have children will optimally 
choose greater consumption when their children are growing up and lower consumption subsequently, implying lower target replacement rates and smaller accumulations of wealth than their childless counterparts. If households do, in fact, behave in this manner, then low levels of retirement saving among younger households may not be a matter of public policy concern because they will catch up later in life and should be aiming for relatively modest replacement rates.

Using Health and Retirement Study (HRS) Consumption and Activities Module (CAMS) data, this paper tests the first-order conditions for the consumption and saving behavior of households over time as children leave home. We examine various categories of household and per-person spending (durables, non-durables, housing, and non-discretionary items). We find that households increase per-capita, non-durable consumption when their disposable income increases, in apparent violation of optimizing behavior, given the traditional formulation of the utility function. The sensitivity analyses suggest this increase is not the result of liquidity constraints. Further, we find no impact on saving behavior or wealth accumulation. The behavior we document is consistent with a variety of plausible utility functions, but the data lacks sufficient detail to distinguish between alternatives, and we therefore leave this for future research. Our findings have important implications for assessments of retirement preparedness. Households who saved little when the children lived at home continue to save little subsequently, despite the increased capacity for saving. These households will arrive at retirement with insufficient wealth to maintain the average level of consumption enjoyed over their working life, let alone the increased standard of living enjoyed after the children leave.

The remainder of the paper is organized as follows. Section II presents the standard utility model used in dynamic programming settings and its testable predictions. Section III 
presents the CAMS data and descriptive statistics. Section IV provides the econometric model and results for consumption. Section V presents the W2 data and descriptive statistics. Section VI provides the econometric model and results for retirement contributions. Section VII concludes.

\section{Model}

The standard permanent income hypothesis model assumes forward-looking agents that derive utility from period-by-period consumption. Abstracting from uncertainty, liquidity constraints, mortality, and other risks, and assuming that the rate of interest equals the rate of time preference, the model predicts that individuals equalize each period's marginal utility of consumption over their lifetimes.

The standard adjustment to the simple model to incorporate changes in household composition, such as the presence of children, involves allowing households to derive utility from person-equivalent units of consumption instead of a composite household consumption. The household thus maximizes:

$$
\sum_{j=s}^{T} \beta^{j-s} n_{j} U\left(\frac{c_{j}}{n_{j}}\right)
$$

where $C_{j}$ is household consumption at time $j$ and $\beta$ is the time discount factor, and $n_{j}$ is the number of people in the household. ${ }^{1}$ If the discount rate equals the interest rate, then the first order condition implies that utility is maximized when per-person consumption is equal in all time periods, or:

\footnotetext{
${ }^{1}$ For exposition, we will assume that adults and children are equivalent and weighted as one each. Because most of the children in our data set are teenaged or older, the equivalent weighting seems reasonable, and we also use equal weighting in the results presented. We later report analysis on the maximum weight a child can receive to have our results match this theoretical framework.
} 


$$
\frac{C_{i}}{n_{i}}=\frac{C_{j}}{n_{j}}
$$

The implications of the first order condition are clear: total household consumption should decrease and parental consumption remain constant, when children leave home. We test the predictions of this model by comparing household and per-person consumption of households before and after children leave home with the consumption patterns of households without changes in the number of children in the household.

\section{Data}

This paper uses CAMS data to investigate whether the consumption of households approaching retirement responds to predictable changes in financial circumstances, such as children leaving home. The CAMS was administered bi-annually from 2001 to 2007 by mail to a random sample of 5,000 individuals drawn from the HRS. While the CAMS collects less precise consumption data than the Consumer Expenditure Survey (CEX), typically used to measure the sensitivity of consumption to changes in income or expenditures (for example, Stephens 2008 and Souleles 1999), it offers the advantage of being a multi-year panel, instead of the one-year panel available in the CEX. Hurd and Rowedder (2006) document that the consumption levels are roughly comparable across these two surveys. The panel feature enables us to use intra-household differences in consumption instead of relying on synthetic cohorts or inter-household differences based on household size. Unlike Browning and Ejrnaes (2009), we examine how consumption changes as children leave the household, not as they enter and age within the household.

We match consumption data measured in one year to the HRS core interview data from the previous calendar year. For example, the 2001 consumption data is matched to $2000 \mathrm{HRS}$ 
data for financial and family structure information. The age of the household respondents is measured in the year of the consumption data. Consumption and income data are normalized to 2007 dollars using the CPI.

Given that the data on consumption and household size are not collected in the same year, we are careful when identifying which households experience children moving out, and when this occurs. The HRS variable for "resident children" is used to determine the number of children living in the household. A household is identified as having children move out if the number of resident children is positive and constant in 2000 and 2002, and falls to zero in both 2006 and 2008. People are defined as "never had resident children” if the resident children variable is zero from 2000 through 2008 inclusive. This group includes households who never had any children, and those whose children had already moved out before 2000. The category “always had resident children” corresponds to a positive and constant number of resident children from 2000 through 2008, inclusive.

The consumption data is grouped into four broad categories for the analysis. Durable consumption includes purchases of large household appliances (refrigerator, washing machine, dishwasher, television set, and computer) and automobiles. Non-discretionary consumption includes vehicle taxes and maintenance, health insurance, and health supplies. Housing includes homeowners insurance as well as standard home expenses (mortgage/rent, electricity, water, heat, and phone). Non-durable consumption includes purchases of housekeeping supplies, personal care products, apparel, leisure and hobby items, vacations, vehicle insurance, any food purchases (including dining out), and gasoline. Non-durable consumption is expected to be the most responsive to changes in household composition. 
Finally, we match our sample to the restricted earnings records made available through the Social Security Administration (SSA). This allows us to construct a proxy for lifetime income, since the permanent income hypothesis tells us that it is lifetime income, not contemporaneous income, which determines the resource constraint.

The base case is aimed at maximizing the sample size. Table 1 outlines the sample selection criteria. We eliminate households not observed in every wave. In order to eliminate confounding household composition issues such as divorce or death, we only include intact and stable households (either single or married) in the sample. The biggest reduction in sample size is due to matching the HRS respondents to the consumption data. Finally, we only include in our analysis individuals between the ages of 52 and 74, and with a positive sampling weight in 2006 . This leaves us with a total sample size of 2,880 observations representing 833 households: 743 never had children in the household, 36 have children who move out, and 54 always have the same number of children living with them.

Table 2 presents the characteristics of the average household in our sample by household composition. Households who always have children living with them differ from the other two groups. They are less likely to be married, have less educated men, and have less wealth. Those who have children move out are younger, and are more likely to be married and working. Tests for differences between the sample means of those who always had resident children or who had resident children move out, and those of households who never had resident children, confirm that the above relationships are statistically significant.

One potential issue with the data that becomes apparent in Table 2 is that the average age of heads of households with children who leave the nest is relatively high - 60 for men and 56 for women, ----- the issue of sample selection. Suchindran and Koo (1992) find that the median 
age of last birth is around 30 for these birth cohorts, suggesting that only a minority will have children living at home after age 55 . This raises issues about whether or not these households who have their last child later in life will behave similarly to other households who experienced different fertility patterns. We add in controls for the woman's age, education, and total number of children to try to address the timing of fertility. Further, we think that if any group will be responsive to the need for retirement saving, it will be those where retirement is more salient. This suggests that our older households may be more likely than most to decrease consumption and increase savings, potentially biasing our results toward confirming the first-order conditions we set out to test (equation 2).

\section{Model and Results}

We compare changes in consumption over time as a function of the household composition. We difference the data in order identify within-household changes in consumption. We compare households with no children, households with children, and households whose children leave, allowing for different intercepts and slopes for each of these groups. The estimating equation is thus:

$\ln \left(C_{t}\right)-\ln \left(C_{t-2}\right)=\alpha+\beta_{1} X_{t}+\beta_{2}$ KidsMoveOut $+\beta_{3}$ KidsAlwaysWit $\square+\beta_{4} X_{t}+$ $\beta_{5} L F P_{t}+\beta_{6} y_{t}+\varepsilon_{t}$

where $\ln \left(C_{t}\right)$ is the natural $\log$ of either total household or per adult equivalent consumption at time $t$. We explore the four types of consumption expenditures separately: non-durables, durables, housing, and non-discretionary spending. $X_{t}$ is a vector of control variables that includes male and female age and age squared, race, marital status, educational attainment, and the labor force participation at time t. We also include a proxy for the lifetime resource 
constraint. This is measured as the average monthly income during the 20 highest years of earnings prior to age 50, adjusted by average wage growth to adjust for differences in both real and nominal earnings across birth cohorts, and put in constant 2007 dollars. LFP $_{\mathrm{t}}$ is a vector of indicators that includes working status at time t-2 and an indicator for changes in working status between $\mathrm{t}$ and $\mathrm{t}-2$. KidsMoveOut is an indicator variable equal to one if a child leaves the household between $\mathrm{t}$ and $\mathrm{t}-2$. This variable measures any change in the trend of consumption over time between households without any children and those whose children move out. This formulation implicitly assumes that moving out has a constant impact on consumption - that is, consumption does not depend on how many years it has been since the child moved out of the house. ${ }^{2} y_{t}$ is set of year dummy variables. KidsAlways With is an indicator variable equal to one if the household had resident children in all four CAMS surveys. This specification allows for the two groups with stable household compositions to have different consumption growth rates. $\beta_{2}$ indicates if consumption trends differ between households without children and those whose children leave home. We will compare the difference between $\beta_{2}$ and $\beta_{3}$ to test for significant differences in the trends of consumption between households whose children remain and those whose children move out. ${ }^{3}$

The results of the baseline specification are presented in Tables 3 and 4 . The columns present the results for non-durable consumption, durable consumption, non-discretionary consumption, and housing consumption, respectively. Table 3 presents the results from the

\footnotetext{
${ }^{2}$ The sample size is too small to test this assumption.

${ }^{3}$ We were initially concerned about a possible endogeneity problem, namely that household composition changes could be driven by other factors, such as decreases in income, that also impact consumption patterns. We explored using the age of the children (when they turn 18 and 22, typical ages of emancipation) as instrumental variables to address this issue. These ages were significant predictors of children leaving the household, however, we could not reject that the children leaving was exogenous (the $\chi^{2}$ statistic was around .4 in all specifications). Thus we present the more efficient OLS regression results.
} 
household-level specifications, while Table 4 presents the per-capita specification results. When the coefficient is small, it approximates, when multiplied by 100 , to the percentage change in consumption resulting from a one-unit increment to the right hand side variable. When the coefficient is larger, the percentage change in consumption is somewhat greater.

Once we control for the household-level fixed effects by first-differencing the data, few of the socio-economic and demographic control variables retain statistical significance. This is to be expected. Although we anticipate, for example, that single households will have lower consumption and those with a college education will have higher consumption, we would not expect to find substantial differences between intact household types in the rate of growth of consumption.

The "kids always with" row shows the percentage growth in consumption of households that had the same number of resident kids throughout, relative to the base case of a household that did not have resident kids at any time during the period. The coefficients for all classes of consumption are invariably small and lacking in statistical significance, irrespective of whether consumption is measured at the household or the per-person level. Both types of household saw each class of consumption grow at approximately the same rate.

The same is not true for households whose kids moved out. The household level coefficients for non-durables and housing consumption are both small and not significantly different from zero. But the per-capita coefficients are both large and significantly different from zero. The non-durables coefficient of 0.409 equates to an increase in consumption of 50.5 percent, and the housing coefficient of 0.325 equates to an increase in consumption of 38.4 percent. The above results suggest that when the kids move out, the parents continue to spend approximately the same total dollar amount as before on non-durables, but enjoy a substantial 
increase in per-capita consumption. The increase in per-capita spending on housing is to be expected because housing expenses include homeowners insurance, mortgage/rent, electricity, water, heat, and phone, most of which would be a function of the size of the house, not the number of people who live within it.

The kids move out coefficients for durables and non-discretionary spending are imprecisely estimated. What is important is that we do not measure differential trends in durable spending, either at the household or per-capita level, based on whether children are present in the household or move out. This suggests that there is not pent-up demand for durable goods; households are not spending the money that used to go to support their children on a new car, boat, or house. Our ability to predict changes in non-discretionary spending is also quite limited. Again, we do not measure any change in non-discretionary income after children leave the household, on either the per-capita or household-level.

There is debate in the existing literature on what is the correct equivalent scale for adult children living in the household. Browning and Ejrnaes (2009) find that teenagers consume as much as an adult, and thus our baseline specification (Table 4) counts everyone as one adultequivalent. Others (National Research Council 1995; Attanasio et al. 1999) suggest that 0.7 is the correct equivalent scale to use, suggesting the denominator should be $n_{j}^{0.7}$, and our results are robust to that measure as well. Indeed, the equivalent scale would have to be less than 0.52 in order to invalidate these findings. Another way to adjust for household composition is to allow children to get a different weight than adults when calculating the number of individuals in the household, where $n_{j}=\left(A_{j}+w K_{j}\right)^{0.7}$, where $\mathrm{A}$ and $\mathrm{K}$ are the number of adults and children, respectively, and $\mathrm{w}$ is the weight given to children, and 0.7 remains the equivalence scale. Adult 
children would have to receive a weight less than two-thirds of an adult to invalidate our findings.

\section{Sensitivity Tests}

The sample specification in the baseline is not very restrictive. For example, we do not limit the sample by the age of the child, which may mean that we are including older children who might be contributing to the household finances, instead of being net consumers of household resources. We also do not limit the sample to pre-retirement households. We make a number of sample restrictions to test the robustness of our findings. The results (see Table 5) of the specification tests are generally robust to a number of sample restrictions. Column 5.1 repeats the base case for per-person, non-durable consumption as shown in Table 4 for comparison purposes. Column 5.2 limits the sample to those households who do not move between 2000 and 2008. Column 5.3 limits the sample to those who are working in all periods, which limits the potential confounding factor of retirement during the observation window. Column 5.4 limits the sample to households whose co-resident children are 30 and under in 2000 in order to limit the inclusion of co-resident children who may be contributing significant financial resources to the household. As the sample specification changes, our estimates remain remarkably robust. In two out of three specification checks, the coefficient of interest $\left(\beta_{6}\right)$ is virtually unchanged, between 0.409 to 0.415 . In 5.3, the sample working in all waves, the coefficient loses both significance and magnitude, but is likely due to the dramatic drop in sample size to 226 person-wave observations.

\section{Other Outcomes}

We have shown that household-level, non-durable consumption does not react to children moving out of the house. However, the sample size we have is admittedly small, and perhaps we 
are mis-measuring a reduction that actually occurs. If household-level consumption does decrease, one would expect the money to show up somewhere else on the household balance sheet. In Table 6, we explore the impact of children moving out on total debt, debt in the form of mortgages, total net worth and its components: non-housing financial wealth, and housing wealth. We do not detect any increases in wealth after children leave the household. Again, this suggests that the increase in disposable income when children are financially independent is being consumed, and not being saved.

\section{Discussion and Conclusions}

We directly test the consumption patterns implied by the first-order conditions of the standard utility function employed in dynamic programming models. This formulation predicts that per-adult equivalent non-durable consumption should remain constant, but total household consumption would decline when children leave the household. We find that the data do not support this type of utility function.

Instead, we find that individuals keep their household-level consumption constant over changes in their household size. This suggests that other utility functions should be explored in order to measure retirement preparedness for younger cohorts more realistically. It could be that behavioral economics theories are at work. For example, mental accounting could mean that households are used to spending a certain amount at the grocery store, and continue to do so even when shopping for fewer people, perhaps by upgrading from chicken to steak. It could mean that omitting leisure from the utility function is an important factor. For example, one may only enjoy high school sports games, typically free, when one’s own child is participating, and once the child leaves the parent finds other, more expensive, activities to occupy his or her leisure 
time. It could also mean that children are consumption goods themselves, and that the parents get utility in equal measure from their and their children's consumption. Unfortunately, the consumption data used do not allow us to separate consumption among individuals, and other consumption data do not allow for a long panel to be analyzed.

The finding that household-level consumption remains constant has important policy implications. First, it suggests that individuals do not increase their retirement savings when they have large increases in disposable income due to their children leaving the nest. Those who save little when they are young, for whatever reason, do not automatically catch up on their savings late in life. Second, the target amount of money one needs to maintain his or her lifestyle in retirement is high, and is equal to the household-level consumption when there are children living in the house. 


\section{References:}

Attanasio, Orazio, James Banks, Costas Meghir, and Guglielmo Weber. 1999. "Humps and Bumps in Lifetime Consumption.” Journal of Economic and Business Statistics, 17:1, 22-35.

Browning, Martin and Mette Ejrnaes. 2009. “Consumption and Children.” The Review of Economics and Statistics, 91(1): 93-111.

Hurd, Michael D. and Rohwedder, Susann. 2006. “Consumption and Economic Well-Being at Older Ages: Income- and Consumption-Based Poverty Measures in the HRS.” Research Paper No. WP 2006-110. Ann Arbor, MI: Michigan Retirement Research Center.

Munnell, Alicia, Francesca Golub-Sass, and Anthony Webb. 2007. "What Moves the National Retirement Risk Index? A Look Back and an Update.” Issues in Brief 7-1. Chestnut Hill, MA: Center for Retirement Research at Boston College.

National Research Council. 1995. “Measuring Poverty: A New Approach.” Washington, DC: National Academy Press.

Scholz, John Karl and Ananth Seshadri. 2008. “Are All Americans Saving ‘Optimally’ for Retirement?” Working Paper, August.

Souleles, Nicholas S. 1999. “The Response of Household Consumption to Income Tax Refunds.” The American Economic Review, 89(4): 947-958.

Souleles, Nicholas S. 2000. “College Tuition and Household Savings and Consumption.” Journal of Public Economics, (77): 185-207.

Stephens, Melvin Jr. 2008. “The Consumption Response to Predicable Changes in Discretionary Income: Evidence from the Repayment of Vehicle Loans.” The Review of Economics and Statistics 90(2): 241-252.

Suchindran, C. M., and Helen P. Koo. 1992. "Age at Last Birth and Its Components." Population Association of America (29): 227-245. 
Table 1. Sample Selection Criteria.

Number of Number of

Households Observations

Provided any type of interview in each wave 2000 - 2008 (inclusive)

8,181

If partnered, same partner in all waves 2000 - 2008 (inclusive);

otherwise single in all waves 2000 - 2008 (inclusive)

6,791

Households cover our criteria for constant number of resident adults, constant number of resident children/grandchildren, or permanent decrease in the number of resident children/grandchildren

Consumption Data

Consumption data is available for each wave between 2001 and 2007 (inclusive) $^{1}$

Age

Age limited to 52 to 74 years of age

Sample Weights

2006 HRS sample household weight is positive

Valid consumption data used for two-wave differences

Treatment Group $^{2}$

The same number of resident children in 2000 \& 2002 and no resident children in 2006 \& 2008

\section{Control Group 1}

No resident children in each wave between 2000 and 2008 and the same number of household members in 2000 - 2006 (inclusive)

\section{Control Group 2}

The same positive number of resident children in each wave between 2000 \& 2008 and the same number of household members in 2000 - 2006

(inclusive)

Source: Authors' calculations from HRS data.

1: Available data means that no more than 10 of the consumption questions have missing data; none of the consumption categories has a value of zero and consumption data is available for enough years to create two-wave differences.

2: For the treatment group, we only have a maximum of three observations per household, since we exclude one observation due to not knowing exactly when the child leaves the household. 
Number of children

Lifetime monthly income

Women

Age in 2001

Less than high school degree

High school degree

Some college education

College education

Men

Age in 2001

Less than high school degree

High school degree

Some college education

College education

Household head

Retired in 2000

Black

Hispanic

Married

Wealth in 2000

Net non-housing financial wealth

Housing wealth

Wealth including second residence

Mortgage

Debt

Change in wealth between 2000 \& 2008

Housing wealth

Wealth including second residence

Mortgage

Debt

Annual consumption in first observation

Durable goods

Housing expenditures

Non-discretionary expenditures

Non-durable expenditures

Annual change in consumption from first to last observation

Durable goods

Housing expenditures

Non-discretionary expenditures

Non-durable expenditures
Net non-housing financial wealth

\section{Total \\ Sample \\ Never Had \\ Resident \\ Children \\ 2000-2008}

3.0

$\$ 4,202$

61

$17 \%$

$57 \%$

$5 \%$

$21 \%$

63

$15 \%$

$50 \%$

$5 \%$

$30 \%$

$52 \%$

$5 \%$

$2 \%$

$65 \%$

192,177

146,033

569,757

40,132

44,129

$-4,619$

67,428

49,407

$-5,635$

$-7,123$

6,174

16,854

7,210

16,352

$-287$

$-76$

1

$-331$

833
3.0
$\$ 4,260$

62

$17 \%$

$56 \%$

$6 \%$

$21 \%$

64

$16 \%$

$49 \%$

$5 \%$

$31 \%$

$55 \%$

$5 \%$

$2 \%$

$66 \%$

207,535

146,962

601,175

38,589

42,711

$-5,723$

67,189

48,825

$-5,710$

$-7,298$

6,017

16,569

7,170

16,441

$-246$

13

24

$-320$

743
Resident

Children

Always Had

Resident

Children

2000-2008

3.2

$\$ 3,918$

Moved

Out

20002008

3.6

$\$ 3,602$

61

$21 \%$

$53 \%$

$0 \%$

$25 \%$

56

$19 \%$

$69 \%$

$0 \%$

$12 \%$

60

$9 \%$

$60 \%$

$6 \%$

$25 \%$

$46 \%$

$3 \%$

$4 \%$

$50 \%$

60

$15 \%$

$53 \%$

$3 \%$

$30 \%$

$23 \%$

$10 \%$

$8 \%$

$82 \%$

76,678

139,414

97,528

350,728

139,682

346,533

54,398

45,066

57,882

47,553

1,011

93,325

53,690

9,104

8,119

8,078

19,859

6,112

14,381

6,774

27,518

53,158

$-30,000$

$-30,000$

$\mathrm{N}$

Notes: HRS 2006 sample weights. All amounts in 2007 dollars.

Source: Authors' calculations from HRS data. 
Table 3. Models of Change in Consumption Behavior - Base Case, Household Level.

Kids Move Out

Kids Always With

Women

Age

Squared age

With less than high school degree

With a high school degree

With some college education

Men

\section{Age}

Squared age

With less than high school degree

With a high school degree

With some college education

Household head

Retired

Change in retirement status

Black

Married

Hispanic

Log monthly life-time earnings

Missing monthly life-time earnings

Total number of children

Constant term

\begin{tabular}{|c|c|c|c|c|c|c|c|c|c|c|c|}
\hline \multicolumn{3}{|c|}{ Non-durables } & \multicolumn{3}{|c|}{ Durables } & \multicolumn{3}{|c|}{ Non-discretionary } & \multicolumn{3}{|c|}{ Housing } \\
\hline Coefficient & & $\begin{array}{c}\text { Standard } \\
\text { error }\end{array}$ & Coefficient & & $\begin{array}{c}\text { Standard } \\
\text { error }\end{array}$ & Coefficient & & $\begin{array}{c}\text { Standard } \\
\text { error }\end{array}$ & Coefficient & & $\begin{array}{c}\text { Standard } \\
\text { error }\end{array}$ \\
\hline \multicolumn{3}{|c|}{3.1} & \multicolumn{3}{|c|}{3.2} & \multicolumn{3}{|c|}{3.3} & \multicolumn{3}{|c|}{3.4} \\
\hline-0.062 & & 0.114 & 0.691 & & 0.869 & -0.343 & & 0.303 & -0.146 & & 0.135 \\
\hline-0.053 & & 0.080 & -0.148 & & 0.613 & -0.082 & & 0.141 & 0.003 & & 0.092 \\
\hline 0.000 & & 0.000 & -0.001 & & 0.002 & 0.000 & & 0.001 & -0.001 & $*$ & 0.000 \\
\hline-0.101 & & 0.071 & 1.142 & * & 0.655 & -0.110 & & 0.132 & -0.063 & & 0.084 \\
\hline-0.042 & & 0.051 & 0.553 & & 0.479 & -0.054 & & 0.097 & 0.009 & & 0.060 \\
\hline-0.049 & & 0.079 & -0.194 & & 0.964 & -0.039 & & 0.166 & -0.126 & & 0.126 \\
\hline 0.059 & * & 0.034 & -0.010 & & 0.312 & -0.040 & & 0.071 & 0.063 & * & 0.036 \\
\hline 0.018 & & 0.085 & -2.912 & ** & 0.832 & 0.018 & & 0.129 & 0.020 & & 0.137 \\
\hline-0.043 & & 0.060 & -0.462 & & 0.503 & -0.089 & & 0.112 & -0.059 & & 0.070 \\
\hline-0.027 & & 0.053 & 0.630 & & 0.425 & 0.036 & & 0.097 & 0.057 & & 0.062 \\
\hline-0.204 & $* *$ & 0.099 & 1.270 & $* *$ & 0.572 & -0.457 & $* *$ & 0.166 & -0.058 & & 0.101 \\
\hline-0.230 & & 0.164 & -1.250 & & 1.019 & -0.222 & & 0.220 & -0.157 & & 0.172 \\
\hline-1.782 & & 1.141 & -0.352 & & 10.668 & 1.230 & & 2.475 & -2.292 & * & 1.253 \\
\hline 0.026 & & 0.017 & -0.182 & & 0.137 & -0.031 & & 0.026 & 0.049 & ** & 0.020 \\
\hline 0.112 & & 0.145 & -1.978 & & 1.212 & -0.243 & & 0.228 & 0.362 & $* *$ & 0.184 \\
\hline-0.004 & & 0.010 & -0.054 & & 0.101 & -0.018 & & 0.019 & -0.003 & & 0.013 \\
\hline
\end{tabular}

$\mathrm{N}$

1440

1440

1440

1440

0.039

0.000

0.084

0.126

0.036

0.000

0.137

0.070

0.062

0.101

0.020

0.184

.013

Notes: The first and second columns report coefficients from OLS models estimated using household level analysis weights; Huber-White standard errors, and significance at 90 ( $)$ and 95 percent $(* *)$ levels. The dependent variable is the change in natural log of non-durable consumption, which is the sum of purchases of housekeeping supplies, personal care products, apparel, leisure and hobby items, vacations, any food purchases (including dining out), vehicle insurance and gasoline. The third and fourth columns present the OLS

coefficients and standard errors where the dependent variable is the change in natural log of durable consumption, which is the sum of the purchases of large household electronics (refrigerator, washing machine, dishwasher, television set, and computer) and automobiles. The fifth and sixth columns present the OLS coefficients and standard errors where the dependent variable is the change in natural log of non-discretionary consumption, which is the sum of vehicle taxes and maintenance, health insurance and health supplies. The last two columns present the OLS coefficients and standard errors where the dependent variable is the change in natural log of housing consumption, which includes property taxes and insurance, as well as standard home expenses (mortgage/rent, electricity, water, heat, and phone). Year indicator variables are also included in the regressions.

Source: Authors' calculations from HRS data. 
Table 4. Models of Change in Consumption Behavior, Per Capita Level.

Kids Move Out

Kids Always With

Women

Age

Squared age

With less than high school degree

With a high school degree

With some college education

Men

Age

Squared age

With less than high school degree

With a high school degree

With some college education

Household head

Retired

Change in retirement status

Black

Hispanic

Married

Log monthly life-time earnings

Missing monthly life-time earnings

Total number of children

Constant term

\section{$\mathrm{N}$}

1440

\begin{tabular}{|c|c|c|c|}
\hline \multicolumn{3}{|c|}{ Non-durables } & \multirow[b]{2}{*}{ Coefficient } \\
\hline Coefficient & & $\begin{array}{l}\text { Standard } \\
\text { error }\end{array}$ & \\
\hline \multicolumn{3}{|c|}{4.1} & \\
\hline 0.409 & & 0.110 & 0.774 \\
\hline-0.051 & & 0.080 & -0.135 \\
\hline 0.055 & & 0.035 & 0.040 \\
\hline 0.000 & & 0.0003 & -0.0004 \\
\hline-0.099 & & 0.071 & 1.042 \\
\hline-0.044 & & 0.051 & 0.521 \\
\hline-0.050 & & 0.079 & -0.145 \\
\hline 0.062 & * & 0.035 & -0.039 \\
\hline-0.001 & ** & 0.0003 & 0.001 \\
\hline-0.077 & & 0.068 & -0.206 \\
\hline-0.026 & & 0.045 & -1.018 \\
\hline 0.019 & & 0.085 & -2.803 \\
\hline-0.046 & & 0.060 & -0.429 \\
\hline-0.025 & & 0.053 & 0.586 \\
\hline-0.195 & ** & 0.100 & 1.248 \\
\hline-0.241 & & 0.163 & -1.134 \\
\hline-1.917 & * & 1.162 & 0.551 \\
\hline 0.026 & & 0.017 & -0.171 \\
\hline 0.114 & & 0.144 & -1.868 \\
\hline-0.005 & & 0.010 & -0.049 \\
\hline-2.058 & * & 1.148 & 0.023 \\
\hline 1440 & & & 1440 \\
\hline
\end{tabular}

Durables

Non-discretionary

Standard

Standard

tandard

error

Housing

\begin{tabular}{|c|c|c|c|c|}
\hline error & Coefficient & error & Coefficient & error \\
\hline & \multicolumn{2}{|c|}{4.3} & \multicolumn{2}{|c|}{4.4} \\
\hline 0.78 & 0.128 & 0.290 & 0.325 & 0.138 \\
\hline 0.546 & -0.080 & 0.141 & 0.004 & 0.092 \\
\hline
\end{tabular}

$(* *)$ levels. The dependent variables are the change in natural log of non-durable, durable, non-discretionary and housing consumption, as described in Table 3 , divided by the number of people in the household. Year indicator variables are also included in the regressions.

Source: Authors' calculations from HRS data. 
Table 5. Robustness Checks: Change in Per Capita Non-Durable Consumption.

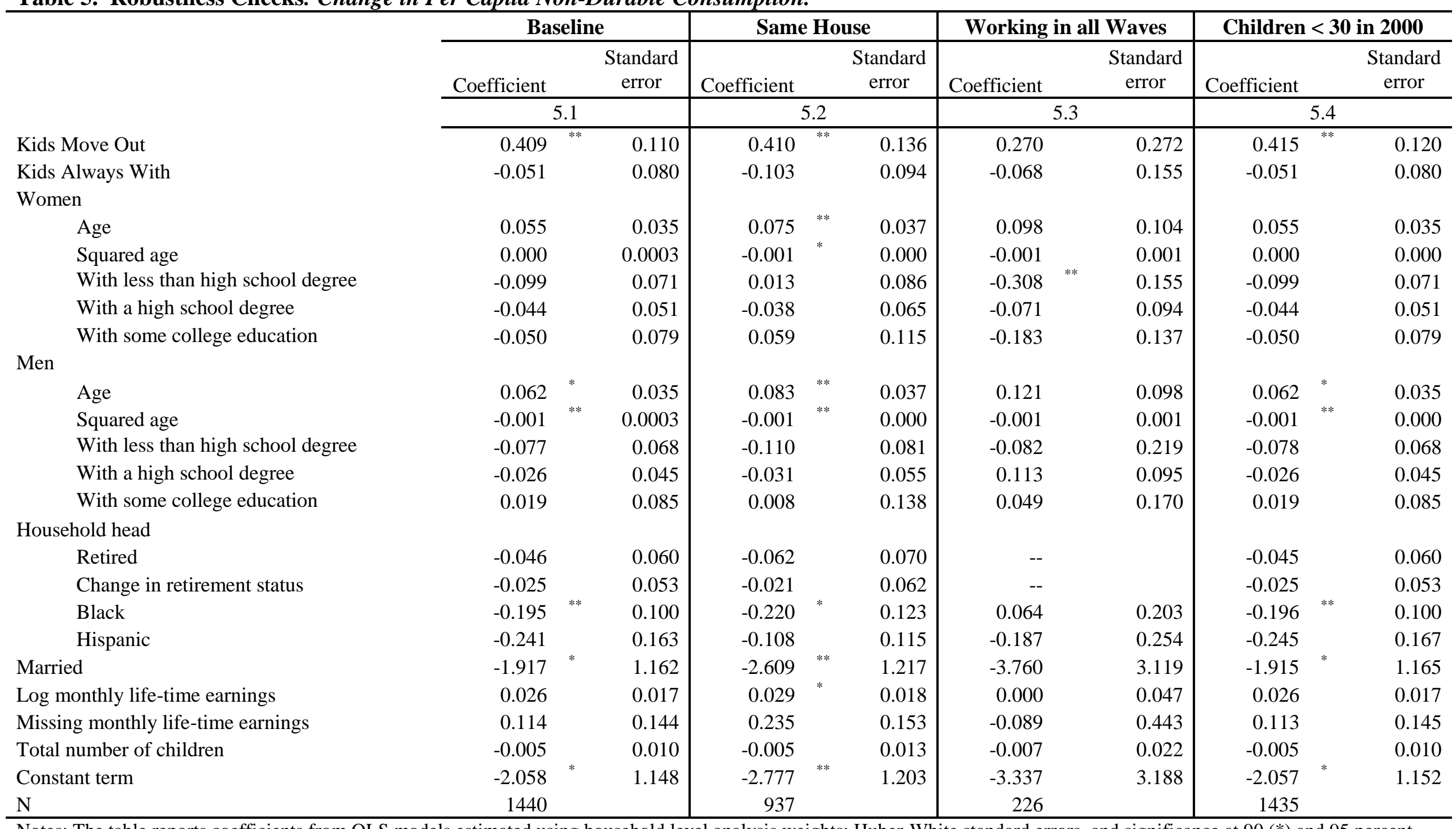

Notes: The table reports coefficients from OLS models estimated using household level analysis weights; Huber-White standard errors, and significance at 90 ( $*$ ) and 95 percent $\left({ }^{* *}\right)$ levels. The dependent variable is the change in natural log of non-durable consumption, as described in Table3, divided by the number of people in the household. Year indicator variables are also included in the regression.

Source: Authors' calculations from HRS data. 
Kids Move Out

Kids Always With

Women

Age

Squared age

With less than high school

degree

With a high school degree

With some college

education

Men

Age

Squared age

With less than high school

degree

With a high school degree

With some college

education

Household head

Retired

Change in retirement status

Black

Married

Hispanic

Log monthly life-time earnings

Missing monthly life-time earnings

Total number of children

Constant term

$\mathrm{N}$

Notes: The table reports coefficients from OL S models estimated using household level

Source: Authors' calculations from HRS data

\begin{tabular}{|c|c|c|c|c|c|c|c|c|c|c|c|c|c|}
\hline \multicolumn{3}{|c|}{ Debt } & \multicolumn{2}{|c|}{ Mortgage } & \multicolumn{3}{|c|}{ Total wealth } & \multicolumn{3}{|c|}{$\begin{array}{c}\text { Non-housing financial } \\
\text { wealth }\end{array}$} & \multicolumn{3}{|c|}{ Housing wealth } \\
\hline Coefficient & & $\begin{array}{l}\text { Standard } \\
\text { error }\end{array}$ & Coefficient & $\begin{array}{l}\text { Standard } \\
\text { error }\end{array}$ & Coefficient & & $\begin{array}{c}\text { Standard } \\
\text { error }\end{array}$ & Coefficient & & $\begin{array}{l}\text { Standard } \\
\text { error }\end{array}$ & Coefficient & & $\begin{array}{l}\text { Standard } \\
\text { error }\end{array}$ \\
\hline \multicolumn{3}{|c|}{6.1} & \multicolumn{2}{|c|}{6.2} & \multicolumn{3}{|c|}{6.3} & \multicolumn{3}{|c|}{6.4} & \multicolumn{3}{|c|}{6.5} \\
\hline-0.586 & & 0.765 & -0.662 & 0.768 & -0.589 & & 0.590 & -1.569 & & 1.123 & -0.315 & & 0.480 \\
\hline 0.066 & & 0.476 & 0.292 & 0.383 & -0.226 & & 0.406 & 0.239 & & 0.980 & -0.569 & * & 0.321 \\
\hline-0.030 & & 0.185 & 0.050 & 0.189 & 0.044 & & 0.114 & -0.172 & & 0.298 & -0.169 & & 0.167 \\
\hline 0.001 & & 0.001 & 0.000 & 0.001 & 0.000 & & 0.001 & 0.001 & & 0.002 & 0.0012 & & 0.001 \\
\hline 0.412 & & 0.461 & 0.278 & 0.351 & -0.406 & & 0.336 & -1.429 & ** & 0.613 & -0.236 & & 0.285 \\
\hline 0.243 & & 0.396 & 0.092 & 0.345 & -0.353 & & 0.261 & -0.831 & $*$ & 0.458 & -0.066 & & 0.223 \\
\hline-0.014 & & 0.797 & -0.024 & 0.825 & -0.134 & & 0.309 & -0.064 & & 0.655 & 0.107 & & 0.395 \\
\hline 0.029 & & 0.178 & 0.048 & 0.184 & 0.038 & & 0.100 & -0.136 & & 0.287 & -0.164 & & 0.156 \\
\hline 0.000 & & 0.001 & 0.000 & 0.001 & 0.000 & & 0.001 & 0.001 & & 0.002 & 0.001 & & 0.001 \\
\hline-0.623 & & 0.416 & -0.470 & 0.416 & 0.399 & & 0.250 & 0.976 & & 0.708 & 0.133 & & 0.275 \\
\hline-0.372 & & 0.363 & -0.276 & 0.357 & 0.489 & ** & 0.178 & 1.014 & ** & 0.487 & -0.232 & & 0.220 \\
\hline 0.024 & & 0.768 & 0.638 & 0.679 & 0.112 & & 0.145 & -0.153 & & 0.737 & -0.047 & & 0.380 \\
\hline-0.330 & & 0.384 & -0.470 & 0.332 & -0.501 & & 0.307 & -0.683 & & 0.638 & -0.215 & & 0.214 \\
\hline 0.177 & & 0.380 & 0.400 & 0.388 & 0.211 & & 0.248 & 0.762 & & 0.583 & -0.092 & & 0.183 \\
\hline-0.795 & & 0.511 & 0.070 & 0.497 & 0.667 & & 0.470 & 4.776 & ** & 1.969 & 0.726 & $* *$ & 0.339 \\
\hline 1.210 & ${ }^{* *}$ & 0.585 & 0.635 & 0.499 & 0.116 & & 0.327 & 0.934 & & 1.313 & -0.384 & & 0.385 \\
\hline-1.046 & & 5.951 & -2.220 & 6.229 & -1.350 & & 3.407 & 4.952 & & 9.894 & 6.126 & & 5.448 \\
\hline 0.037 & & 0.092 & -0.022 & 0.089 & 0.037 & & 0.106 & -0.130 & & 0.140 & 0.142 & & 0.093 \\
\hline 0.400 & & 0.808 & -0.067 & 0.726 & 0.381 & & 0.864 & -1.228 & & 1.262 & 0.958 & & 0.770 \\
\hline 0.048 & & 0.073 & 0.061 & 0.071 & 0.011 & & 0.068 & 0.095 & & 0.120 & -0.093 & * & 0.055 \\
\hline-0.550 & & 6.013 & -2.073 & 6.290 & -1.764 & & 3.460 & 4.826 & & 9.827 & 5.589 & & 5.516 \\
\hline 1440 & & & 1440 & & 1440 & & & 1440 & & & 1440 & & \\
\hline
\end{tabular}

ite standard errors, and significance at $90(*)$ and 95 percent $(* *)$ levels. The dependent 


\section{RECENT WORKING PAPERS FROM THE}

\section{CENTER FOR RETIREMENT RESEARCH AT BOSTON COLLEGE}

Overview of the CRR 2009 Retirement Survey

Alicia H. Munnell, Norma B. Coe, Kelly Haverstick, and Steven A. Sass, October 2010

State Wage-Payment Laws, the Pension Protection Act of 2006 and 401(k) Saving Behavior Gary Engelhardt, October 2010

Asset Cycles and the Retirement Decisions of Older Workers

Jan Ondrich, October 2010

Price Deflators, the Trust Fund Forecast, and Social Security Solvency

Barry Bosworth, October 2010

The Impact of a DROP Program on the Age of Retirement and Employer Pension Costs Samson Alva, Norma B. Coe, and Anthony Webb, September 2010

Housing Consumption in Late Life: The Role of Income, Health Shocks, and Marital Shocks

Douglas A. Wolf and Janet M. Wilmoth, September 2010

Adjusting Social Security for Increasing Life Expectancy: Effects on Progressivity Courtney Monk, John A. Turner, and Natalia A. Zhivan, August 2010

Work and Retirement Patterns for the G.I. Generation, Silent Generation, and Early Boomers: Thirty Years of Change

Richard W. Johnson, Barbara A. Butrica, and Corina Mommaerts, July 2010

Spousal Health Shocks and the Timing of the Retirement Decision in the Face of ForwardLooking Financial Incentives

Courtney Harold Van Houtven and Norma B. Coe, June 2010

Incorporating Employee Heterogenity Into Default Rules for Retirement Plan Selection Gopi Shah Godi and Colleen Flaherty Manchester, May 2010

Accurately Measuring Health Over the Life Course

Fabian Lange and Doug McKee, May 2010

Getting to the Top of Mind: How Reminders Increase Saving

Dean Karlan, Margaret McConnell, Sendhil Mullainathan, and Jonathan Zinman, April 2010

The Shrinking Tax Preference for Pension Savings: An Analysis of Income Tax Changes, 1985-2007

Gary Burtless and Eric Toder, March 2010

All working papers are available on the Center for Retirement Research website

(http://crr.bc.edu) and can be requested by e-mail (crr@bc.edu) or phone (617-552-1762). 